\title{
'Biobanks' "engagements": engendering trust or engineering consent?'
}

\section{ALAN PETERSEN ${ }^{1}$}

\begin{abstract}
The rapid development of biobanks internationally reflects the considerable expectations attached to the exploitation of genetics knowledge. However, establishing consent and legitimacy for the new generation of biobanks is not without its challenges because they tend to be prospective in nature, involving the collection of DNA, personal medical and lifestyle data generally held over a very long period of time for unspecified research purposes. Thus far, biobanks have tended to be established ahead of wide-ranging debate about their broad implications. Making specific reference to the 'engagement' processes employed by UK Biobank during its establishment phase, this article focuses on the politics of 'public engagement'. It examines the context of arguments for 'public engagement', drawing attention to how particular approaches to 'engagement' within biobank projects may serve to limit debate on substantive questions arising from their development. Unless biobanks' 'engagements' substantially involve publics in deliberations about their development, it is argued, publics are likely to become distrustful of projects and perhaps resist other similar population-based health initiatives in the future.
\end{abstract}

\section{Introduction}

The rapid development of population-wide genetic databases, or 'biobanks', reflects the great expectations that pertain to genetics knowledge in the wake of the Human Genome Project and other gene-mapping initiatives. By promising to disentangle the genetic, lifestyle and environmental determinants of disease, especially those with a complex aetiology such as dementia, heart disease and stroke, biobanks are seen to hold considerable promise for advancing understanding of disease causation and thus improving healthcare in the years ahead. Biobanks have been endorsed by many authorities, including science bodies and public health organisations, such as the World Health Organisation which sees benefits at the international level, for eradicating haemoglobin disorders and infectious diseases. ${ }^{2}$ In recent years, a number of countries have developed or stated their intention to develop such collections, including Iceland, Estonia, Canada (Quebec), Taiwan, Japan, France, Sweden, Singapore, the US, Australia, and the UK.

The term 'biobank' has been applied to different kinds of collections. They may be either 'prospective', involving the sampling of participants from the outset of a study and the subsequent tracking of their health, or 'retrospective', involving the sampling and collection of information from those who already have developed a particular disease. ${ }^{3}$ Genetic databases, including those comprising samples from populations or families with particular conditions, have been in existence for over 30 years and have not been the subject of substantial debate, controversy or resistance. However, the new generation of biobanks face a particular problem in gaining consent and 
legitimacy because they tend to be prospective in nature, involving the collection of DNA and personal medical and lifestyle data generally held over a very long period of time, potentially two to three decades, for unspecified research purposes. Given the novelty of this approach to research, and the uncertainties that it entails, it is hardly surprising that in recent years questions have been raised about the adequacy of informed consent and other established ethical principles. ${ }^{4}$ Unfortunately, the public discourse about biobanks has been limited thus far by a particular dominant framing of issues in terms of benefits and the management of risks - the latter including public responses to developments. Like many science and technology developments, biobanks have been established ahead of wide-ranging discussion among different publics and stakeholder groups about their value, form and impacts. Health technologies in particular are assumed to be necessarily aligned to 'the public good', and objections, when they are voiced, are seen as mostly resolvable through rational administrative means, such as the use oversight bodies and ethics and governance protocols. While there has been considerable debate about the 'ethical' implications of biobanks, there has been less discussion about the broad socio-political and governmental implications of biobank developments.

This article focuses on the politics of biobanks' 'engagements'. It examines the context of arguments for public engagement, drawing attention to how particular approaches to 'public engagement' within biobank projects may serve to limit debate on substantive questions arising from their development. These questions may include whether such projects are likely to be successful and represent a valid use of public resources and are therefore worthy of public support, who is likely to benefit from future research, and whether they have or are likely to have any unforeseen exclusionary and discriminatory effects. Making specific reference to the 'engagement' processes employed by UK Biobank during its establishment phase, it is argued that the question of how biobanks seek to engage publics, in particular the extent to which they allow for debate on substantive issues and for publics to shape their development are likely to be crucial to publics' willingness to support such developments in the future. If biobanks' 'engagements' are perceived by publics as merely mechanisms for engineering consent for projects whose aims, establishment and methods of management have already been decided rather than as means to substantially involve publics in deliberations about their development, it is argued, publics are likely to become distrustful of projects and perhaps resist other similar population-based health initiatives in the future.

\section{The purported 'crisis of trust'}

The issue of consent and legitimacy has become salient in the UK and some other countries in recent years as a consequence of the purported 'crisis of trust' in authorities and in particular in the regulatory systems governing biomedical technologies. I have described it as a purported 'crisis' because, as Brian Wynne rightly points out, in the UK at least this is based upon a 'creation myth' that proposes that before the 'crisis', dating from approximately 1996 and the mad-cow disease fiasco, publics trusted scientists. ${ }^{5}$ It also implies that members of 'the public' hold a unitary view towards 'science' when in fact there are multiple discourses and practices which are labelled as 'science'. ${ }^{6}$ In the UK, public disquiet about 
authorities' response to mad cow disease (BSE) and the GM controversy, combined with a series of medical scandals, in the late 1990s and early 2000s (eg, Alder Hey, Bristol Royal Infirmary, the Harold Shipman affair) are perceived by many authorities as evidence of a failure of regulation in the fields of biomedicine and biotechnology that has engendered mistrust. Evidence of mistrust is seen to be revealed by surveys, such as that undertaken by the Office of Science and Technology and the Wellcome Trust in 2000 which revealed respondents' 'amazement' in science, but their 'low level of confidence in regulation and the Government'. ${ }^{7}$ Concerns about a 'crisis of trust' have been echoed in various reports such as the Science and Society report of the House of Lords Select Committee on Science and Technology (2000). ${ }^{8}$ Consequently, developing means to exploit the opportunities offered by new technologies without undermining public trust has become a priority among many science groups and policymakers in recent years. Trust - or rather mistrust - has become a core issue for contemporary risk governance. ${ }^{9}$ Numerous government and social science reports have called for a revised approached to scientific decision making in a context of social and technical uncertainty. ${ }^{10}$ Recent calls for 'upstream' public engagement, for example in the UK's Royal Society and Royal Academy of Engineering's report on nanoscience and nanotechnologies, ${ }^{11}$ and a series of engagement projects on nanotechnologies funded through the Office of Science and Innovation at the Department of Trade and Industry (ScienceWise) are indicative of this current emphasis in policy. ${ }^{12}$

The trajectory of biobank developments and the nature of public responses have varied cross-nationally, reflecting different histories, cultures, and political systems. European countries have tended to adopt a more precautionary approach than the US and some newly industrialising countries to new biotechnologies. ${ }^{13}$ In some contexts, biobanks have developed with little public involvement or debate. However, the rapid global sharing of information and experiences among countries, occasioned by the internet and the rise of supranational organisations, has facilitated learning across jurisdictions and some degree of international harmonisation of approach to biobank development, in relation to ethics, governance and public engagement. For example, harmonisation of approach to genomic and biobank research is encouraged by the Human Genome Organization (HUGO), whose Statement on Human Genomic Databases, published in December 2002, includes a 'Recommendation' that 'Public engagement is a prerequisite of public responsibility'. ${ }^{14}$ The not-for-profit Public Population Project (P3G), an international consortium comprising members of organisations involved in biobanks and large-scale epidemiology projects, aims to standardise methodologies and improve coordination across different biobank projects. ${ }^{15}$ This also includes standardisation of ethics, governance and public engagement. For the proponents of UK Biobank, the controversy surrounding the Icelandic Health Sector Database, especially in relation to presumed consent and commercial involvement, provided a model of how not to develop a biobank. ${ }^{16}$ The Joondalup Health Project in Western Australia, which provides a pilot for the proposed WA Genome Health Project, has taken a strong cue for its approaches to engagement from UK Biobank. ${ }^{17}$ The question of whether it is meaningful or feasible to develop a cross-national system of ethics and governance for biobanks has been a topic of some recent discussion among social scientists and biobank proponents. ${ }^{18}$ However, despite this interchange of ideas and expert knowledge, biobank proponents 
and managers seem to have reflected little on the assumptions that inform 'engagement' efforts, including their main purpose, the rationale for adopted approaches, and methods of assessment.

\section{Why 'engage' 'the public'?}

A number of arguments for 'engaging' 'the public' in new technology developments can be made. Fiorino's work, although focusing on citizen participation in relation to environmental risk decisions, provides a useful preliminary reference in this regard. ${ }^{19}$ As Fiorino observes, all democratic societies have to find means of dealing with the effects of existing technologies and anticipate and evaluate the consequences of new ones. Risk analysts have tended to view issues in technical and analytic terms and assume a rational and probabilistic approach to risk and its management. Benefits and risks of decisions can be broadly agreed upon and objectively assessed and any potential risks effectively managed through a range of administrative mechanisms. In this view, there is no need to involve 'the public' in any substantial way since decisions are ones that can be determined by science and the deliberation of supposedly impartial experts on the 'science facts'. However, as Fiorino argues, there are at least three arguments for eschewing this technocratic orientation and involving publics in decisions. ${ }^{20}$ The instrumental argument is that participation is seen to lend legitimacy to decisions and lead to better results. Without effective means for including citizens in the decisions that affect them, the crisis of confidence in risk management will only deepen. Further, a widening of participation is likely to improve decision-making, by incorporating a broader range of values into decisions and reduce the chance of error. The substantive argument is that lay judgements about risk are equally valid as those of experts. A range of examples may be cited to show that non-experts are often well placed to make judgements about risk. They may be more aware of issues and problems and see solutions overlooked by the experts. Lay publics employ their own constructions of risk ('lay epidemiology') employing everyday rationalities drawn from personal experience and informed by community value systems. ${ }^{21}$ The normative argument is that there is an incompatibility existing between democratic ideals and the technocratic orientation. The latter overlooks the implicit values within policies and disenfranchises publics that ought to be involved in policy development. Value judgements and ethical considerations need to inform policies and citizens should be allowed to participate in decisions that affect them and their communities. ${ }^{22}$

According to this schema, participatory mechanisms may be assessed in terms of the extent to which the outcomes of participatory strategies advance stated ideals. For example, if the aim is to encourage debate and participation in decision-making processes then survey questionnaires fare poorly. They remove scientific questions from their social and cultural contexts. ${ }^{23}$ Citizens' review panels, on the other hand, are a mechanism that allow more scope for the involvement of non-experts and have the potential to inform policymakers' deliberations, although they cannot claim to be representative of affected publics and impact on only a small number of people. ${ }^{24}$ The range of established methods is highly diverse, including, in addition to the above, workshops and seminars, focus groups, consensus conferences, citizens' juries, and deliberative polling. However, all have limitations and unintended implications and 
are premised upon particular constructions of 'science and technology' and 'the public' and 'its' levels of 'understanding'. While Fiorino's schema provides a useful basis for assessing how effective outcomes are in advancing predefined ideals, it assumes that there can be clear agreement among various stakeholders about those ideals, methods and outcomes of participation. However, as Renn notes, 'Confusion about the goals of citizen participation accompanies every practical application'. While citizens, experts, administrators and stakeholders may agree that participation is desirable, experience has shown that they are likely to have different reasons for doing so and varying ideas on how the process should be conducted. ${ }^{25}$ There is often a lack of consensus on the standards of assessment, and indeed on the need for assessment at all, as well as on the aims of evaluation and the appropriate research methodologies. ${ }^{26}$ Questions have been asked about whether these participatory mechanisms are or can be compatible with formal political processes, and whether they should complement or supplant existing decision-making processes (for example, whether they can strengthen or provide an alternative to representative government). Further, concerns have been raised about the criteria for assessing whether participating groups are representative of the wider population and whether such representation can only ever be more than symbolic. ${ }^{27}$

Rarely do policymakers specify whom 'the public' is that they aim to 'engage' or seem to recognise that different strategies may be needed for different publics or that certain strategies may exclude particular groups. For example, physically and mentally disabled people may find it difficult to participate in certain engagement activities, and those whose first language is not English or whose levels of literacy are poor may find it difficult to make sense of written materials and surveys or be involved in certain activities such as citizens' juries. Every adopted method reflects assumptions about the population that is to be 'engaged', their levels of knowledge, their ability to comprehend issues, their readiness to be involved in the engagement process, their propensity to act on issues in certain ways, and so on. The method may help shape the discussion by lending legitimacy to the project and excluding those who are opposed to it or who are unable or unwilling to 'engage' in expected ways. Evidence of the effectiveness of particular participatory strategies is often inconclusive or negative, particularly in relation to changing the technological culture or the social dynamics affecting technologies. ${ }^{28}$ Like 'transparency', 'public engagement' is something that many people can agree upon as being a positive ideal, but the question of what it means in practice, and the longer term implications of using particular engagement strategies, is often far from clear. In policymaking, the use of such terms may serve to obscure growing bureaucratisation and the introduction of new insidious forms of control. ${ }^{29}$ For these reasons, there is a need for greater precision and caution when making claims about 'engagement' and its effectiveness.

\section{The lingering influence of the 'knowledge deficit' model}

For many technological innovations, 'engagement' efforts continue to be promoted on the assumption that they are needed for overcoming publics' 'knowledge deficits', which is required to attain greater public acceptance of science. ${ }^{30}$ It is assumed that more or better knowledge or improved communication will enhance receptivity to 
innovations. As Brunk notes, this denies the 'knowledge deficits' that also exist with experts, for example in relation to the concerns of publics about certain aspects of technologies. In his example of the controversy over the impact of Americanproduced GM corn on Mexican maze agriculture, farmers voiced their distress at the failure of experts and policymakers to address their worries. Background papers and the statements of authors pertaining to the effects of GM maize on farmers' health, environment and culture failed to acknowledge the cultural and religious significance of maize as an ancestral heritage. The use of the language of 'risk' in this context was therefore inappropriate. ${ }^{31}$ This example illustrates well the impossibility of separating 'facts' and 'values' in relation to GM and other technological innovations, and of how experts and policymakers tend to value the former above the latter. ${ }^{32}$

Recently, there has been increased questioning among social scientists about the extent to which the emphasis on 'public engagement' represents a move away from the deficit model of public understanding. Wynne, for example, notes that there has been a tendency for public deficit models of mistrust in science to be constantly reinvented: he identifies six versions since 1990, beginning with 'public deficit of understanding of scientific knowledge' to the most recent version which suggests that 'Public responses are emotional, dependent, epistemically empty, [and] gullible to manipulation'. ${ }^{33}$ In his view, this re-invention of deficit models is indicative of the absence of reflexivity in the institutional culture and policy itself. Consequently, the whole relationship between the new enterprise of public engagement with science, and public confidence in science, deserves more careful scrutiny and critical attention. Importantly, however - because it is often overlooked - before defining what public engagement with science should involve and what it can be expected to produce, an enlightened and reflective diagnosis of the possible nature and causes of the problem of 'public mistrust of science' is required. If it does prevail, then of what precisely is there mistrust? Under what conditions and in what contexts, and for what reasons? Unless we understand these questions, we are in no position to respond constructively and effectively to the problem. So far, scientific institutions have managed to avoid facing the possibility that they themselves are part of (not exclusively) the original cause. $^{34}$

Like Brunt, Wynne identifies 'knowledge deficits' within science itself, particularly in relation to its constructions of 'the public', including the view that 'the public' 'mistrusts science because it is ignorant of science', is 'scared of "uncertainty"' or is 'only concerned about threats to its own safety'. ${ }^{35}$ As he concludes, it is counterproductive to try to instrumentally engender public trust in science by 'public engagement' or other means. Indeed, 'it is a contradiction in terms to instrumentalize a relationship which is supposed to be based on trust. ${ }^{36}$ Part of the solution to the purported problem of the 'crisis of trust' then is to engender within institutions greater self-awareness and questioning about their own assumptions and images of science and of the public. ${ }^{37}$ This involves acknowledgement that trust relations are characterised by ambivalence and uncertainty and are likely to be provisional. ${ }^{38}$ As Cunningham-Burley notes, rather than viewing scepticism and ambivalence as a problem to be overcome, it can be used as a resource to increase levels of debate and promote shared decision making. ${ }^{39}$ 


\section{UK Biobank: its 'public engagement' thus far}

UK Biobank represents an interesting case for the exploration of 'public engagement' in practice. In its early phase development, the project embodies many of the assumptions and tendencies identified and critiqued above. First proposed in 2000, as a collaborative venture between the Wellcome Trust, the Medical Research Council and the Department of Health (and now funded also by the Scottish Executive and Northwest Regional Development Agency), UK Biobanks has been developed in a context involving a mixture of great expectations about the applications of genetic knowledge in the wake of the Human Genome Project and other 'gene-mapping' initiatives combined with concerns about the perceived failures of earlier public consultation processes which are believed to have contributed to a 'decline of trust'. ${ }^{40}$ A major challenge for proponents of the project has been to convey the benefits of UK Biobank in order to establish consent and legitimacy for its development and yet be seen to be paying cognisance to publics' views without leading to a backlash of the kind seen to have plagued GMOs. As noted, a particular problem facing many biobank developments is their prospective nature and the collection of data for unspecified research purposes. In various forums, proponents of UK Biobank have sought to emphasise the benefits of the project, for public health, science and the economy, as well as offering reassurances that the project is developed in a transparent manner, adheres to established ethics and governance protocols, and is competently managed. Various documents produced by the UK Biobank's partners have stressed the project's adherence to good governance and its ongoing receptivity to public concerns. ${ }^{41}$ In other words, 'public engagement' has proceeded as a kind of risk management strategy rather than as a genuine attempt to involve publics in shaping the overall aims, direction and management of the project or to open debate about the project's value and implications.

From the outset, the project partners have made much of their efforts to 'consult' 'the public' and pertinent stakeholders, including in relation to the ethics and governance framework, through various mechanisms. These include panels and workshops involving members of 'the general public' from across the UK and specific groups (eg, people with disabilities or diseases, religious and community groups), meetings with industry and focus groups with primary healthcare workers. ${ }^{42}$ Regular updates of web postings, which include key documents relating to the project (eg, ethical and governance protocols) and summaries of 'consultations', lend this impression of transparency and openness. However, the rationale for the use of this particular mix of methods and their adequacy has not been open to public scrutiny and discussion through this and other means and does not appear to have been the subject to questioning by the project's partners. It is difficult to know the kinds of deliberations about the project that have not been made public. Consultation exercises are stakeholder oriented in that they typically include only those who have expressed an interest in the issues, and their potential for expanding decision making is reliant on prior decisions about their scope. ${ }^{43}$ A 'public consultation' report on 'the ethical and management issues surrounding the proposed BioBank UK [sic] project', commissioned by the Wellcome Trust and MRC and undertaken by an independent public policy consultancy (People Science and Policy Ltd), provides no explanation for the rationale for the selected methods for the research (a series of group 
discussions with the proposed target population (45-69)) and for how the sample was selected and offers no assessment of the level of confidence that can be ascribed to the findings and recommendations given the small sample size and its lack of representation from all socio-economic groups and proposed recruitment regions within the UK. (The fact that the sample is not representative is acknowledged in the report.) ${ }^{44}$ The text of the report indicates that the 'project team' was on hand to 'explain' participants' various 'misunderstandings' and 'confusions' (eg, about the representativeness of the sample group) and offer 'reassurances' (eg, regarding the monitoring of health), which suggests that the process was as much about educating the participants as an attempt to garner wide-ranging views on the project and its value. Further, many of the resulting recommendations concern ways to improve participation rates and communication processes rather than to address substantive concerns raised about the project (eg, 'Taking part must be made as easy as possible. People may look for excuses to justify their inertia'; 'Setting out how this study adds value to existing work will sway some waverers. This needs to be clear in the initial recruitment material.'; 'The role of GPs must be clarified and publicised.' $)^{45}$ In other words, the consultation reveals a conception of 'the public' as ignorant and anxious and in need of more or better or more clearly presented information; in short, this is a version of the 'public deficit' model in evidence in a number of other areas of science and technology communication. The tone of the consultation document, including the wording of questions, responses to concerns raised, the kind of recommendations made and the use of language as above, suggest that the process was tightly managed, allowing little scope for deviation from the predefined agenda. At the time of writing, there is no evidence to indicate that there has been a move away from this model of 'engagement' or that project partners have reflected on the purpose and adequacy of the approach.

Despite these efforts to present UK Biobank in a positive light, almost from the outset the project has been the subject of criticism on a number of fronts. Some scientists have questioned the scientific basis of the project and see it as inefficient approach for investigating many of the diseases that are likely to be of greatest interest. Members of parliament have raised concerns about the adequacy of the consultative processes and the methodology. The activist group Gene Watch has questioned whether the project was 'a good use of public money' and suggested it 'could undermine public trust in medical research'. ${ }^{46}$ The 'consultations' themselves revealed some reservations or concerns about the project, including the potential for commercial profiteering, and the involvement of the MRC and the Wellcome Trust, which were seen as 'subject to pressure from pharmaceutical companies and the Government, and too willing to work to an agenda against the interests of people with disabilities. ${ }^{47}$ The project also attracted some early adverse media attention, with at least one report referring to the potential to 'sell off DNA secrets' to private drug companies. ${ }^{48}$ These criticisms and expressed concerns may be indicative of the proponents' failure to involve publics and stakeholders in wide-ranging debate about the project and its uncertainties from the outset. During the period of initial 'consultation', the project received relatively little news coverage and the public visibility of the project has remained relatively low despite the fact that the project is expected to begin recruiting participants in 2007. Since the 'consultations', there appears to have been little effort by the partners to generate broad debate about the nature of the project or the 
substantive issues it raises, including concerns raised by participants in the workshops and by critics during the early stage of its development.

UK Biobank's public consultation has itself been the subject of severe criticism from, for example, the House of Commons Select Committee:

It is our impression that the MRC's consultation for Biobank has been a bolt-on activity to secure widespread support for the project rather than a genuine attempt to build a consensus on the project's aims and methods. In a project of such sensitivity and importance consultation must be at the heart of the process not at the periphery. ${ }^{49}$

This suggests the need for some fundamental reflection upon what the 'consultations' were meant to achieve and how methods for involving different publics in decision making and debates might be improved, assuming the project is to proceed as planned. (The starting date for the recruitment of participants has been delayed a number of times.)

A number of potential challenges confront UK Biobank in the future as it begins to recruit and establish its database, some of which became evident during the integrated pilot phase, undertaken between February and June 2006. These include a number of practical problems: How most effectively to access contact details for the main recruitment phase? (For a range of reasons recruitment through Primary Care Trusts proved time-consuming and difficult and it was recommended that this should be undertaken through 'just a few national points of access'.) How to encourage participants to volunteer and discourage them from withdrawing, given the periodic demands on participants' time and energies? (The pilot for the project suggests that on average 90 minutes was required for the initial health assessment visit.) How to ensure an adequate response rate from people of different ages, genders, ethnicities and geographical locations? (The rate of confirming an appointment to attend an assessment visit tended to be higher in older people and women. ${ }^{50}$ In addition, a number of more fundamental and longer-term uncertainties exist. These include: economic conditions affecting private sector involvement (changing commercial investment priorities, with perhaps a shift away from biotechnology research - a highly feasible scenario given shareholders' demands for quick profits); healthcare workers' responses to recruitment (perhaps medical resistance, as happened in Iceland) ${ }^{51}$ and adverse media coverage of the project or other biomedical research, which may have 'contaminating' affects on publics' views on and support for the project. These all suggest the need for wide-ranging debate with various constituencies, including healthcare workers, commercial partners, the media and various publics. However, any attempt to significantly involve these groups in an ongoing way is likely to present a risk to the viability of the project. A particular challenge is how to make transparent to participants and publics the nature of the study and its methods, limitations and uncertainties and risks, without arousing concerns and undermining confidence in the project. There is an inherent tension between 'openness' and maintaining confidence in the project, since the former suggests consideration of the many uncertainties that surround such collections, which always have the potential to give rise to fears and thus resistance to the project. 


\section{Conclusion}

A fundamental question that needs to be addressed by developers and managers of biobanks before they deploy particular 'engagement' strategies is what they aim to achieve by 'public engagement'. If the aim is to instrumentally engender public trust rather than generate debate about the purpose and implications of such collections and/or to involve publics in shaping the direction of their development, then, as Wynne argues, 'engagement' efforts are likely to be counter-productive. ${ }^{52} \mathrm{UK}$ Biobank is an interesting and instructive example of 'engagement' in practice since its partners have made much of their efforts to 'engage' publics and the project has been presented as 'set[ing] a new standard for ethics and governance'. ${ }^{53}$ Yet, while UK Biobank partners have made considerable efforts to convey a positive image of the project, including its 'openness', inclusiveness and its managers' trustworthiness, ${ }^{54}$ their 'consultations' thus far have allowed limited scope for wide-ranging exploration of the substantive issues raised by the project. These include, for example, concerns regarding the nature and level of commercial involvement and the prospect of discrimination, which were raised by those participating in the project's workshops for 'the general public' and by others. UK Biobank's 'engagement' efforts thus far convey the impression that these have been largely about managing perceived mistrust and engineering consent rather than creating the conditions for trust. If the aim has been to engender trust then it is difficult to see how this can be achieved when the public visibility of the project has been so low and little apparent effort has been made to widely publicise the project and encourage deliberation on its various implications. In the event, as noted, the project has attracted a number of criticisms, including, significantly, several relating to its processes of consultation. There has been little indication of how many if not most of these criticisms and concerns will be addressed, and it is difficult to see how early 'engagement' experiences have shaped plans for ongoing 'consultation', which has been promised as a feature of the project. There remain many uncertainties regarding the project, despite its plans to begin recruiting participants in 2007.

This analysis suggests that among proponents and developers of biobanks there is a need for greater self-awareness of and reflection on the relationship between science and its publics and on the assumptions that currently inform 'engagement' practices. If 'engagement' efforts are undertaken with the aim of incorporating non-experts' viewpoints and value judgements into decisions and allowing for exploration of publics' ambivalences and concerns about biobanks, rather simply adding legitimacy to decisions already made by the 'experts', then this requires a willingness by developers and managers of biobanks to encourage scrutiny and criticisms of scientific constructions and biases. In particular, there is a need for acknowledgement that there is no consensus among scientists about the scientific case for biobanks and that the potential value of biobanks is highly contested. ${ }^{55}$ As Wallace argues, there has been a tendency to exclude 'expert' debates within the consultation process, which has a distorting effect on discussion. In the case of UK Biobank, a focus in 'consultations' thus far on 'ethics and governance' issues has served to 'narrow' debate on a range of substantive questions that the project gives rise to, such as the role of science in society and the value and diverse implications of population-wide 
repositories of this kind. ${ }^{56}$ Finally, once the aim of 'engagement' has been clarified, there needs to be greater clarity about the rationale for the use of particular methods of 'engagement'. Assumptions about 'the public' and its 'understanding' that underlie the use of certain methods need to be exposed. The effectiveness of different methods for ascertaining the views of those who are generally excluded from scientific debates also needs to be questioned. It needs to be recognised that particular methods may work to marginalise some groups and that new approaches may be needed to engage particular groups - for example, minority ethnic groups and people with disabilities. In the absence of reflection on the assumptions underlying current engagement endeavours and efforts to redress 'deficits' in experts' understanding of 'the public' there is the danger that 'public engagement' efforts will serve to exacerbate rather than allay any existing public concerns and that publics will be mistrustful of other population-based health innovations in the future.

\section{Acknowledgements}

The research which informs this article was undertaken while I was a Visiting Professorial Fellow at the ESRC Genomics Research and Policy Forum in September and October 2006. I would like to thank members of the Forum for the hospitality and generosity shown me during my stay. An earlier version was presented to the workshop organised jointly by the Forum and the School of Law and I am grateful for their support in hosting this event. In particular, I would like to thank Clare de Mowbray who arranged my accommodation and answered my numerous queries, Matthew Harvey who introduced me to members of the Forum and helped make my stay comfortable, Renata Gertz who helped organise the workshop, and Nadia Kanellopoulou, who suggested a number of the references which were drawn on for this article.

\footnotetext{
${ }^{1}$ School of Law and Social Science, Faculty of Social Science and Business, University of Plymouth, UK a.petersen@plymouth.ac.uk

${ }^{2}$ See, eg, WHO. 2002. Genomics and World Health: Report of the Advisory Committee on Health Research. Geneva: WHO.

${ }^{3}$ R. Twyman. Biobanks: The Long Game. Wellcome Science 2007; 5.

${ }^{4}$ TRAMES: Journal of the Humanities and Social Sciences (Special issue: Human genetic databases: ethical, legal and social issues) 2004; 8 (2/3); Also see R. Tutton \& O. Corrigan. 2004. Genetic Databases: Socio-ethical Issues in the Collection and Use of DNA. London and New York: Routledge. ${ }^{5} \mathrm{~B}$. Wynne. Public engagement as a means of restoring public trust in science - hitting the notes, but missing the music? Community Genetics 2006; 9: 211-220.

${ }^{6}$ Ibid, pp.211-212

${ }^{7}$ Office of Science and Technology and The Wellcome Trust. 2000. Science and the Public: A Review of Science Communication and Public Attitudes to Science in Britain. London: The Wellcome Trust.

${ }^{8}$ House of Lords Science and Technology Committee. 2000. Science and Technology. Third Report.

Available at http://www.parliament.the-stationeryoffice.co.uk/pa/ld199900/ldselect/ldsctech/38/3801.htm

${ }^{9}$ J. Barnett, A. Carr and R. Clift. 2006. Going public: Risk, trust and public understanding of nanotechnologies. In Nanotechnology: Risk, Ethics and Law. G. Hunt and M. Mehta, eds. Earthscan.

${ }^{10}$ A. Irwin and M. Michael. 2003. Science, Social Theory and Public Knowledge. Open University Press.

${ }^{11}$ Royal Society and Royal Academy of Engineering. 2004. Nanoscience and Nanotechnologies:

Opportunities and Uncertainties. London. The Royal Society.
} 
${ }^{12}$ A. Petersen, A. Anderson, C. Wilkinson and S. Allan. Nanotechnologies, risk and society: editorial. Health, Risk and Society 2007; 9 (2).

${ }^{13}$ S. Jasanoff. 2005. Designs on Nature: Science and Democracy in Europe and the United States. Princeton and Oxford. Princeton University Press.

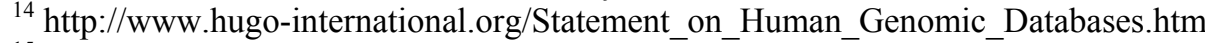

15 http://www.p3gconsortium.org/

${ }^{16} \mathrm{G}$. Palsson. Forthcoming 2007. The rise and fall of a biobank: the case of Iceland. In H. Gottweis and A. Petersen, eds. Biobanks: Governance and Comparative Perspective. London and New York: Routledge.

${ }^{17}$ B. McNamara and A. Petersen. Forthcoming 2007. Consenting and consulting citizens: ethics as governance in biobanks in Australia and the UK. H. Gottweis and A. Petersen, eds. Biobanks: Governance in Comparative Perspective. London and New York: Routledge.

${ }^{18} \mathrm{~J}$. A. Bovenberg. Towards an international system of ethics and governance of biobanks: a "special status" for genetic data? Critical Public Health 2005; 15 (4): 369-383.

${ }^{19}$ D. J. Fiorino. Citizen participation and environmental risk: a survey of institutional mechanisms. Science, Technology and Human Values 1990; 15 (2): 226-243.

${ }^{20}$ Ibid, pp.227-228.

${ }^{21}$ C. Davison, G. Davey Smith and S. Frankel. Lay epidemiology and the prevention paradox: the implications of coronary candidacy for health education. Sociology of Health and Illness. 1991; 13 (1): $1-19$.

${ }^{22}$ Fiorino, op cit. note 19, pp.227-228

${ }^{23}$ A. Irwin and M. Michael. 2003. Science, Social Theory and Public Knowledge. Maidenhead: Open University Press.

${ }^{24}$ Fiorino. op cit. note 19, pp.236-238.

${ }^{25}$ O. Renn, T. Webler and P. Wiedmann. 1995. A need for discourse on citizen participation: evaluating models of environmental discourse. In Fairness and Competence in Citizen Participation: Evaluating Models of Environmental Discourse. O. Renn, T. Webler and P. Wiedmann, eds. Dordrecht. Kluwer Academic Publishers: pp.1-16.

${ }^{26}$ S. Joss. 1995. Evaluating consensus conferences: necessity or luxury? In Public Participation in Science: The Role of Consensus Conferences in Europe. S. Joss and J. Durant, eds. London. Science Museum: pp.89-108.

${ }^{27}$ A. Armour. 1995. The citizens' jury model of public participation: a critical evaluation. In Fairness and Competence in Citizen Participation: Evaluating Models of Environmental Discourse. O. Renn, T. Webler and P. Wiedmann, eds. Dordrecht. Kluwer Academic Publishers: pp. 175-188. Also see J. Stewart, E. Kendall and A. Coote. 1994. Citizens' Juries. London: Institute for Public Policy Research. ${ }^{28}$ T. Cronenberg. 1995. Do marginal voices shape technology? In Public Participation in Science: The Role of Consensus Conferences in Europe. S. Joss and J. Durant, eds. London: Science Museum: 125133.

${ }^{29}$ Renn op cit. note 25, p5. B. Cooke and U. Kothari. 2001. Participation: the New Tyranny? London: Zed Books; A. Petersen and D. Lupton. 1996. The New Public Health: Health and Self in the Age of Risk. London: Sage.

${ }^{30}$ C. G. Brunk. Public knowledge, public trust: understanding the "knowledge deficit". Community

Genetics 2006; 9: 178-183. Irwin and Michael, op cit. note 23, pp.47-55.

${ }^{31}$ Brunk, op cit. note 30 .

${ }^{32}$ Irwin and Michael op. cit. note 23, p.8.

${ }^{33}$ Wynne, op. cit. note 5, p.214.

${ }^{34}$ Ibid, p. 213.

${ }^{35}$ Ibid, p. 216.

${ }^{36}$ Ibid, p. 219.

${ }^{37}$ Ibid, p. 220.

${ }^{38}$ S. Cunningham-Burley. Public knowledge and public trust. Community Genetics 2006; 9: 204-210.

${ }^{39}$ Ibid, p.209.

${ }^{40}$ For an extended discussion of the project's nature, aims and 'consultative' methods see A. Petersen. 2005. Securing our genetic health: engendering trust in UK Biobank. Sociology of Health and Illness 2005; 27 (2): 271-292.

${ }^{41}$ Ibid, pp. 279-286.

${ }^{42}$ Ibid, pp. 281-282. 


\footnotetext{
${ }^{43}$ Royal Commission on Environmental Pollution (RCEP). 1998. $21^{\text {st }}$ Report: Setting Environmental Standards. London: The Stationery Office. In A. Irwin and M. Michael, eds. Science, Social Theory and Public Knowledge. Maidenhead: Open University Press.

${ }^{44}$ People Science and Policy Ltd. 2002. Biobank UK: A Question of Trust: A Consultation Exploring and Addressing Questions of Public Trust. Report Prepared for the Medical Research Council and The Wellcome Trust. People Science and Policy Ltd: London.

${ }^{45} \mathrm{http}: / /$ www.ukbiobank.ac.uk/docs/consultation.pdf (accessed 27 February 2007)

${ }^{46}$ V. Barbour. UK Biobank: a project in search of a protocol? The Lancet, 2003; 361: 1734-8. House of Commons Select Committee on Science and Technology. 2003. Third Report (March). Available at http://www.publications.parliament.uk/pa/cm200203/cmselect/cmsctech/132/13208.htm. I. Gibson. 2002. Petition on 'Biobank'. House of Commons Hansard Debates, 3 July 2002. Available at http://www.publications.parliament.uk. Gene Watch UK. 2002. Biobank UK - a good research priority? Human Genetics and Health. Parliamentary Briefing. 3 November. Available at http://www.genewatch.org/HumanGen/Publications/MP_Briefs.html\#MP_3.

${ }^{47}$ The Wellcome Trust and MRC, 2000. Public Perceptions of the Collection of Human Biological Samples. Available at http://www.ukbiobank.ac.uk/docs/perceptions.pdf

${ }^{48}$ Barnett and Hinsliff, 2001. Fury at plan to sell of DNA secrets. The Observer, 23 September, p. 1.

${ }^{49}$ House of Commons Select Committee on Science and Technology, op. cit. note 46, p.7.

${ }^{50}$ UK Biobank Coordinating Centre. 2006. UK Biobank: Report of the Integrated Pilot Phase. 19 September 2006. Stockport, Cheshire: UK Biobank Coordinating Centre.

${ }^{51}$ Palsson, op. cit. note 26.

${ }^{52}$ Wynne, op. cit. note 5.

${ }^{53}$ Comments made by Professor John Newton, Chief Executive of UK Biobank, at the launch of UK Biobank's Ethics and Governance Framework in 2003. See Medical Research Council.. UK Biobank takes shape. MRC Network. Winter 2003. Available at http://www.mrc.ac.uk/Utilities/Documentrecord/index.htm?d=MRC002444.

${ }^{54}$ Petersen, op. cit. note 40, pp.286-287.

${ }^{55}$ H. M. Wallace. The development of UK Biobank: excluding scientific controversy from ethical debate. Critical Public Health 2005; 15 (4): 323-333.

${ }^{56}$ See special issue on 'Biobanks: challenges for "ethics", Critical Public Health 2005; 15 (4).
} 